\title{
Study of the Removal of Aniline from Wastewater via MEUF Using Mixed Surfactants
}

\author{
Hai-Yan Fu ${ }^{1,2, *}$, Zhi-Bin Zhang ${ }^{3}$, Tian Chai ${ }^{1,2}$, Guo-He Huang ${ }^{1,4}$, Shu-Jie Yu ${ }^{1}$, Zheng Liu ${ }^{1,2}$ \\ and Pan-Feng Gao ${ }^{1,2}$ \\ 1 College of Environmental Science and Engineering, Xiamen University of Technology, Xiamen 361024, \\ China; chait@xmut.edu.cn (T.C.); huangg@uregina.ca (G.-H.H.); yushujie-xiaopang@163.com (S.-J.Y.); \\ liuzh@xmut.edu.cn (Z.L.); gaopf@xmut.edu.cn (P.-F.G.) \\ 2 Key Laboratory of Environmental biotechnology, Fujian Province University, Xiamen 361005, China \\ 3 Xiamen Lianchuangda Technology Co., Ltd., Xiamen 361009, China; zhibin1006@163.com \\ 4 Faculty of Engineering, University of Regina, 3737 Wascana Parkway, Regina, SK S4S 0A2, Canada \\ * Correspondence: fuhy@xmut.edu.cn; Tel.: +86-592-629-1151
}

Academic Editor: Jiangyong $\mathrm{Hu}$

Received: 15 April 2017; Accepted: 19 May 2017; Published: 23 May 2017

\begin{abstract}
In this paper, the anionic surfactant sodium dodecyl sulfate (SDS) and the bio-surfactant rhamnolipid are mixed to achieve micellar-enhanced ultrafiltration, and the associated aniline removal efficiency is investigated. The impacts of five factors, including the mixing ratio of the SDS concentration to the rhamnolipid concentration, the $\mathrm{pH}$, the salinity, the operating pressure, and the aniline concentration in the feed solution, on the aniline rejection and the membrane permeation flux are explored. The aniline rejection mechanism of the rhamnolipid mixture surfactant is analyzed. This study shows that the effect of these factors on the aniline rejection is in the order of $\mathrm{pH}>$ mixing ratio $>$ operating pressure $>$ aniline concentration $>$ salinity; the factors that affect the membrane permeation flux are in the order of mixing ratio $>$ operating pressure $>$ salinity $>\mathrm{pH}>$ aniline concentration. Under the optimal test conditions (i.e., SDS:rhamnolipid $=8: 2, \mathrm{pH}=5$, salinity $=250 \mathrm{mmol} / \mathrm{L}$, operating pressure $=3.5 \mathrm{bar}$, aniline concentration $=1.5 \mathrm{mM}$ ), the verification test results showed an aniline rejection of $78.36 \%$.
\end{abstract}

Keywords: micellar-enhanced ultrafiltration; aniline; rhamnolipid; orthogonal experiment

\section{Introduction}

With the rapid development of the chemical industry in China in recent years, aniline has become a widely used compound. Similarly, chemical production has produced a significant amount of aniline wastewater. Such wastewater produces ecological hazards and threatens the human population's health [1-3]. The current aniline wastewater treatment methods mainly include chemical methods, physical methods, and biological methods [4-6]. Among them, micellar-enhanced ultrafiltration technology (MEUF) has already become a relatively mature organic treatment technology employed abroad. MEUF offers advantages including a simple operation, a high recovery efficiency, and a high removal efficiency [7-11], all of which make MEUF promising for aniline wastewater treatment. However, researchers worldwide have mainly used chemical surfactants [12,13], while studies on the applications of bio-surfactants in micellar-enhanced ultrafiltration remain limited [14-16]. However, chemical surfactants have disadvantages, such as high critical micelle concentrations (CMCs), high dosages, unfavorable economics, and the likely consequence of secondary pollution. Moreover, a single chemical surfactant has a limited solubilizing capacity and poor repair efficiency. Compared with the chemical surfactant, the bio-surfactant with a lower CMC and toxicity and better environmental compatibility attracts much attention $[17,18]$. Recently, by utilizing the excellent 
characteristics of both the chemical surfactant and bio-surfactant to maximize the degradation efficiencyand reduce environmental pollution, increasing attention has been paid to composite surfactants [19], which have a relative strongly affinity for enhancing the performance of the surfactant and reducing the repair cost.

This paper investigates the feasibility of the composite surfactant micellar-enhanced ultrafiltration treatment of organics. A typical surfactant, SDS, and an environmentally friendly bio-surfactant, rhamnolipid, are mixed for enhanced ultrafiltration, and the aniline rejection and membrane permeation flux are investigated.

\section{Materials and Methods}

\subsection{Materials}

Aniline was produced by Shanghai Hushi Chemical Ltd., Shanghai, China, analytically pure; the surfactant sodium dodecyl sulfate (SDS) was produced by Shanghai Hushi Chemical Ltd., chemically pure; rhamnolipid was produced by HuzhouZijin Biological Technology Ltd., Zhejiang, China, 100\% pure, CMC $50 \mathrm{mg} / \mathrm{L}$.

\subsection{Test Equipment}

The test equipment is shown in Figure 1. The surfactant was added to the aniline wastewater, and the mixture was stirred evenly with a glass rod. After allowing it to stand for $15 \mathrm{~min}$, the mixture was introduced into the membrane equipment through a peristaltic pump, while the penetrant solution and concentrated solution flowed back to the water pool. The operating pressure was controlled to regulate the reflux. The membrane operating pressure was displayed on a pressure gauge, and the dialysate flux was displayed on a rotameter. At the end of each experiment, the surfactant was cleaned from the equipment first, and the equipment was then cleaned using a membrane detergent for $20 \mathrm{~min}$ to restore the ultrafiltration membrane to its original flux for the next experiment.

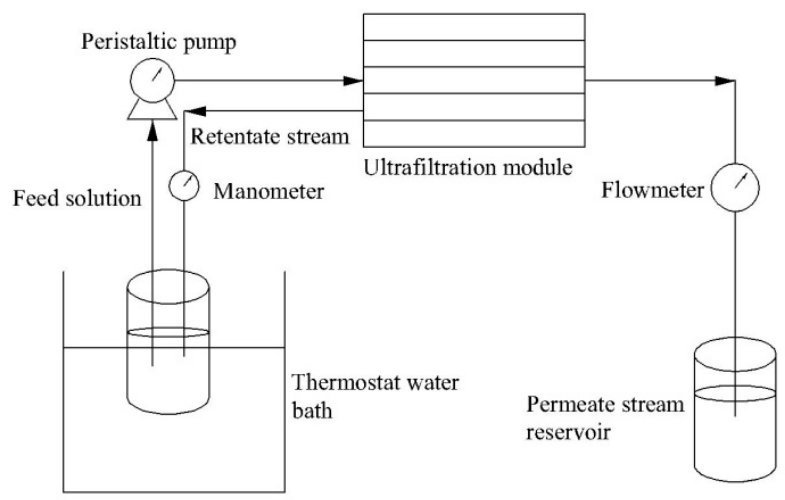

Figure 1. Schematic diagram of the ultrafiltration setup.

\subsection{Analysis Items and Method}

The effects of the surfactant mixing ratio, feed solution $\mathrm{pH}$, salinity, operating pressure, and aniline concentration in the feed solution on the MEUF were analyzed.

The aniline concentration was measured using a Shimadzu ultraviolet visible spectrophotometer (UV-2450, Shimadzu, Kunshan, Jiangsu, China); the wavelength of maximum absorbance was $280 \mathrm{~nm}$.

The aniline rejection was calculated by the following formula:

$$
\mathrm{R}=1-\frac{\mathrm{C}_{\mathrm{p}}}{\mathrm{C}_{\mathrm{f}}}
$$


where $C_{p}$ is the aniline concentration in the dialysate $(\mathrm{mg} / \mathrm{L}), \mathrm{C}_{\mathrm{f}}$ is the aniline concentration in the feed solution $(\mathrm{mg} / \mathrm{L})$, and $\mathrm{R}$ is the aniline rejection.

The permeation flux was calculated by the following formula:

$$
\mathrm{J}=\frac{\mathrm{Q}}{\mathrm{A} \Delta \mathrm{t}}
$$

where $\mathrm{Q}$ is the penetrated volume $(\mathrm{L}), \mathrm{t}$ is the operation time $(\mathrm{h}), \mathrm{A}$ is the flat membrane surface $\left(\mathrm{m}^{2}\right)$, and $\mathrm{J}$ is the membrane permeation flux $\left(\mathrm{L} /\left(\mathrm{m}^{2} \cdot \mathrm{h}\right)\right)$.

\section{Results and Discussion}

\subsection{Effect of the Surfactant Mixing Ratio on the MEUF Aniline Rejection Efficiency}

The aniline concentration in the feed solution was $1 \mathrm{mmol} / \mathrm{L}$, the operating pressure was 2 bar, the $\mathrm{pH}$ was 7 , the $\mathrm{NaCl}$ salinity was $200 \mathrm{mmol} / \mathrm{L}$, and the surfactant concentration was $10 \mathrm{CMC}$. The mixing ratios of SDS:rhamnolipid were 2:8, 4:6, 5:5, 6:4, and 8:2, and the effect of the surfactant concentration in the feed solution on the aniline rejection efficiency was investigated.

The results (Figure 2) show that the aniline rejection increased with an increasing mixing ratio of SDS:rhamnolipid, the membrane permeation flux decreased with an increasing mixing ratio of SDS:rhamnolipid, and membrane fouling further decreased the flux. These results show that a higher rhamnolipid concentration results in a lower aniline rejection, which may have occurred because aniline in neutral water bodies is mainly removed by surfactant solubilization. As a bio-surfactant, rhamnolipid has a complex structure and a relatively large molecular structure, forming large and sparse micelles, which are not conducive to capturing aniline molecules in solution and thus result in a lower removal rate. The experiment showed that a mixed surfactant has a better aniline removal efficiency than pure rhamnolipid. On the one hand, this result occurs because the mixture reduces the rhamnolipid CMC and creates more micelles to solubilize more aniline. However, SDS molecules are embedded in micelles so that rhamnolipid micelles are denser and more compact, which helps to capture and remove aniline molecules using ultrafiltration technology. The membrane permeation flux decreases with an increasing SDS concentration. This effect occurs because with an increasing SDS concentration, more micelles with dense and compact structures are created; these micelles are more likely to be compacted on the membrane surface to form a filter cake and reduce the membrane flux. Moreover, small micelles are also more likely to enter membrane openings and thus cause more severe membrane fouling.

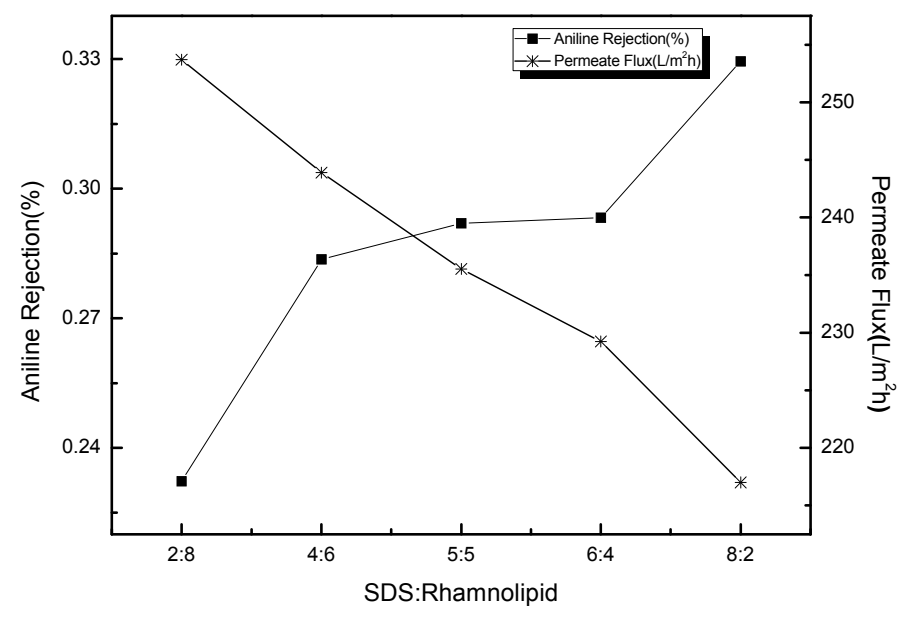

Figure 2. Effect of the percent of sodium dodecyl sulfate (SDS) and rhamnolipid on aniline rejection and permeate flux. 


\subsection{Effect of the Feed Solution $p H$ on the MEUF Aniline Rejection Efficiency}

The aniline concentration in the feed solution was $1 \mathrm{mmol} / \mathrm{L}$, the operating pressure was $2 \mathrm{bar}$, the SDS:rhamnolipid ratio was 5:5, the $\mathrm{NaCl}$ salinity was $200 \mathrm{mmol} / \mathrm{L}$, and the feed solution $\mathrm{pH}$ values were $5,6,7,8$, and 9 . The effect of the feed solution $\mathrm{pH}$ on the aniline rejection efficiency was investigated. The test results are shown in Figure 3.

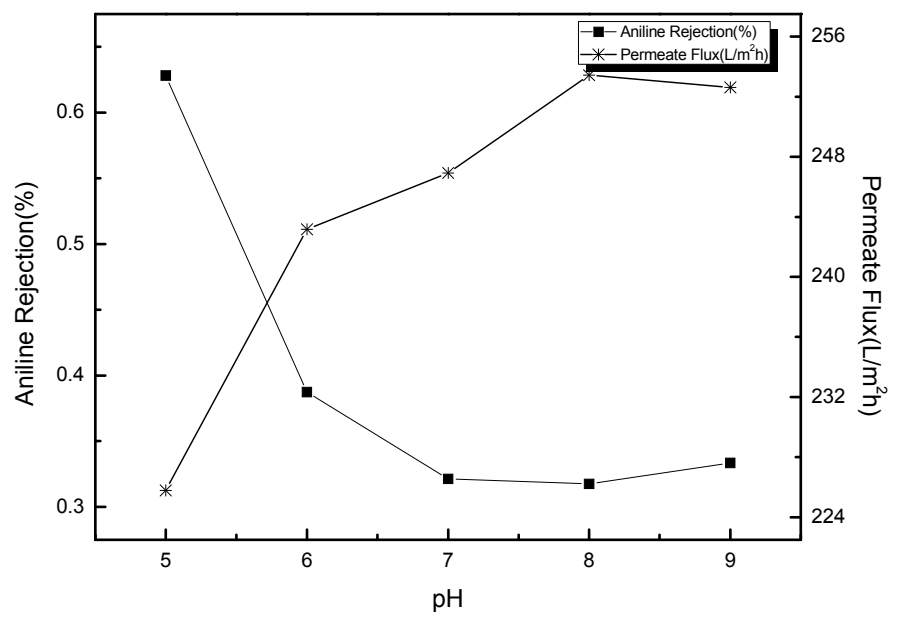

Figure 3. Effect of $\mathrm{pH}$ on aniline rejection and permeate flux.

The results show that with an increasing solution $\mathrm{pH}$ value, the aniline rejection declines initially and then gradually rises, and the membrane permeation flux increases with an increasing $\mathrm{pH}$ value. When the $\mathrm{pH}$ value is 5 , the aniline rejection is the highest. An aniline hydrating solution in water is alkaline in nature, so an acid solution facilitates aniline hydrolysis. Both rhamnolipid and SDS are anionic surfactants, and aniline hydrolysis generates positively charged aniline cations. Therefore, micelles can adsorb more aniline ions via electrostatic adsorption and remove aniline ions by ultrafiltration rejection. According to the physiochemical properties of rhamnolipid, rhamnolipid can easily dissolve in an alkaline solution and is only slightly soluble in an acid solution. Therefore, an increasing $\mathrm{pH}$ may facilitate rhamnolipid dissolution and thereby reduce the solution viscosity and increase the membrane flux.

\subsection{Effect of Salinity on the MEUF Aniline Rejection Efficiency}

The aniline concentration in the feed solution was $1 \mathrm{mmol} / \mathrm{L}$, the operating pressure was $2 \mathrm{bar}$, the $\mathrm{pH}$ was 7 , the SDS:rhamnolipid mixing ratio was 5:5, and the salinities (i.e., $\mathrm{NaCl}$ concentrations) were $100,150,200,250$, and $300 \mathrm{mmol} / \mathrm{L}$. The effect of the feed solution salinity on the aniline rejection efficiency was investigated.

The results (Figure 4) show that with an increasing feed solution salinity, the aniline rejection initially increased and then decreased, while the membrane permeation flux initially decreased and then increased. When $\mathrm{NaCl}$ was added, the aniline rejection increased, while the membrane flux decreased. This result may have occurred because the addition of $\mathrm{NaCl}$ reduces the surfactant $\mathrm{CMC}$ and creates more micelles. In addition, because of the existence of chloride ions and sodium ions, the electric charges on SDS and rhamnolipid are partially neutralized, so the electrostatic exclusion effect between the surfactants is weakened [20]. This effect makes it easier to create micelles with higher density, which increases the probability of aniline capture and solubilization but also aggravates membrane fouling. Moreover, the existence of ions also lowers the electric charge and potential on the micelle surface [21,22]. Therefore, sodium ions can compete with hydrolytic aniline ions, reducing the probability of the electrostatic adsorption of aniline by micelles and affecting the removal efficiency. 


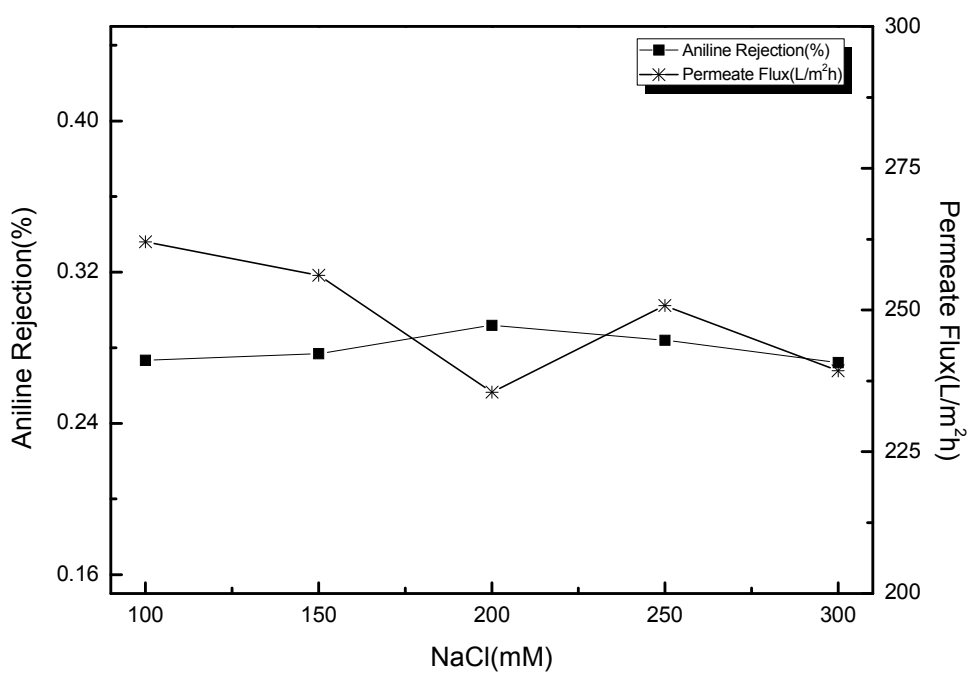

Figure 4. Effect of the electrolyte concentration on aniline rejection and permeate flux.

\subsection{Effect of the Operating Pressure on the MEUF Aniline Rejection Efficiency}

The aniline concentration in the feed solution was $1 \mathrm{mmol} / \mathrm{L}$, the $\mathrm{pH}$ value was 7, the SDS:rhamnolipid mixing ratio was $5: 5$, the $\mathrm{NaCl}$ salinity was $200 \mathrm{mmol} / \mathrm{L}$, and the operating pressure settings were 2, 2.5, 3, and 3.5 bar. The effect of varying the operating pressure on the aniline rejection efficiency was investigated. The test results are shown in Figure 5.

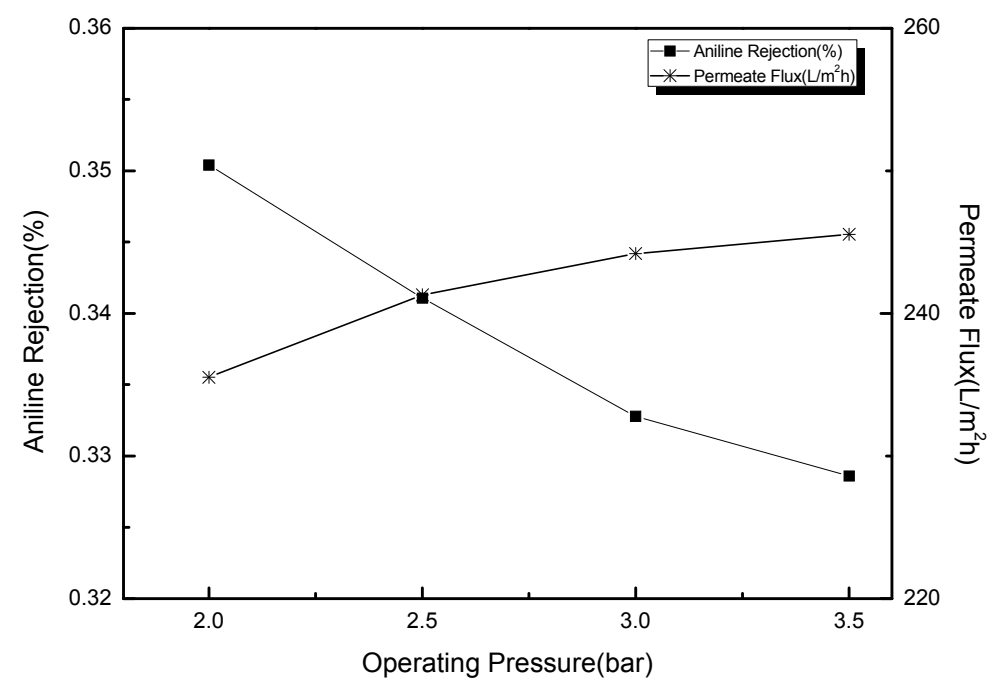

Figure 5. Effect of the operating pressure on aniline rejection and permeate flux.

The result shows that the aniline rejection decreased with an increase in pressure and that the membrane permeation flux increased with an increase in pressure. Some studies held the view that [23] under a relatively high pressure, the micelle shape may be altered: micelles are compressed, and their internal space is squeezed, so bonds between the organics and the micelles are constrained, which reduces the solubilized aniline. Moreover, the micelle concentration on the membrane surface increases, and the micelles are more likely to pass through the membrane pores to carry aniline into the penetrant. Therefore, the aniline rejection declines. When the operating pressure increases, more micelles aggregate on the membrane surface, which further boosts the concentration polarization effect, further reducing the membrane flux. 


\subsection{Effect of the Aniline Concentration in the Feed Solution on the MEUF Aniline Rejection Efficiency}

The feed solution $\mathrm{pH}$ value was 7, the SDS: rhamnolipid mixing ratio was 5:5, the $\mathrm{NaCl}$ salinity was $200 \mathrm{mmol} / \mathrm{L}$, the operating pressure was $2 \mathrm{bar}$, and the aniline concentrations in the feed solution were $0.5,1,1.5,2$, and $3 \mathrm{mmol} / \mathrm{L}$. The effect of varying the operating pressure on the aniline rejection efficiency was investigated.

The results (Figure 6) show that with an increasing aniline concentration in the feed solution, the aniline rejection increased initially and then declined, while the membrane permeation flux remained largely unchanged. When the aniline concentration increased from $0.5 \mathrm{mmol} / \mathrm{L}$ to $1.5 \mathrm{mmol} / \mathrm{L}$, the aniline rejection increased. This result occurred because the solution had already generated a certain number of micelles; with an increasing aniline concentration, an excess of micelles in the water can remove more aniline via solubilization. When the aniline concentration exceeded $1.5 \mathrm{mmol} / \mathrm{L}$, the micelle adsorption in the solution was already saturated, so aniline could not be solubilized, and its concentration increased. This effect leads to more aniline moving into the dialysate and results in reduced aniline rejection.

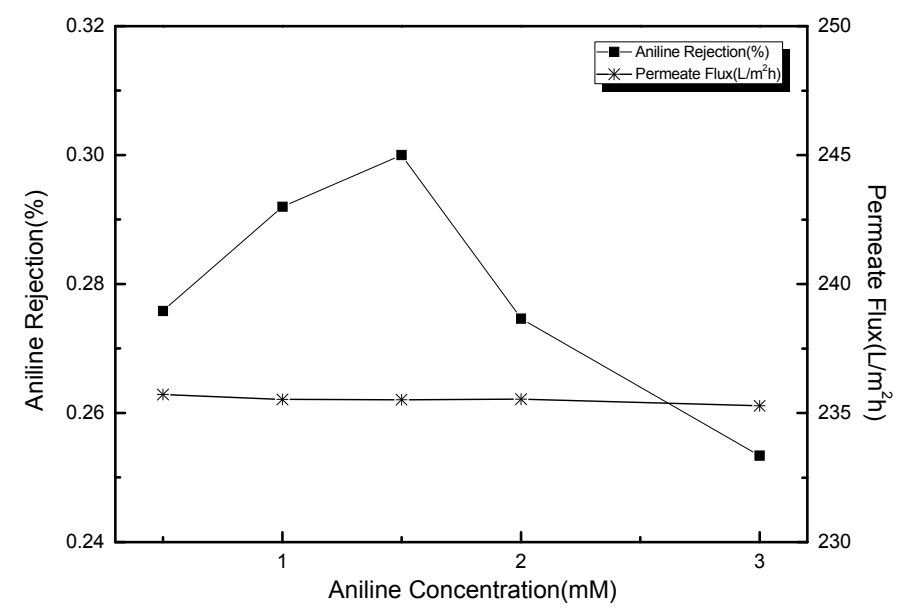

Figure 6. Effect of the aniline concentration on aniline rejection and permeate flux.

\subsection{Orthogonal Solubilization Test}

The orthogonal experiment was adopted to optimize the experimental results. The orthogonal test involved five factors, four levels, and two indices. Among them, the five factors are the mixing ratio of SDS to rhamnolipid (A), the solution $\mathrm{pH}(\mathrm{B})$, the salinity (C), the operating pressure (D), and the initial concentration of aniline (E). Table 1 lists the five factors and four levels; the two indices are the aniline rejection and the membrane permeation flux. The orthogonal test results are listed in Table 2. Curves of the factors with significant impacts on the aniline rejection and the membrane permeation flux are shown in Figure 7. The orthogonal test results for the aniline rejection and the membrane permeation flux are shown in Figure 8.

Table 1. Factors and levels.

\begin{tabular}{cccccc}
\hline \multirow{2}{*}{ Level } & \multicolumn{5}{c}{ Factor } \\
\cline { 2 - 6 } & Mixing Ratio (A) & $\mathbf{p H}(\mathbf{B})$ & Salinity (C) (mmol/L) & Operating Pressure (D) (bar) & Aniline Concentration (E) (mM) \\
\hline 1 & $2: 8$ & 5 & 100 & 2 & 0.5 \\
2 & $4: 6$ & 6 & 150 & 2.5 & 1 \\
3 & $6: 4$ & 8 & 200 & 3 & 1.5 \\
4 & $8: 2$ & 9 & 250 & 3.5 & 2 \\
\hline
\end{tabular}


Table 2. Results of the orthogonal experiment.

\begin{tabular}{|c|c|c|c|c|c|c|c|c|}
\hline \multirow{2}{*}{\multicolumn{2}{|c|}{$\begin{array}{c}\text { Number of } \\
\text { Experimental Set }\end{array}$}} & \multicolumn{5}{|c|}{ Level } & \multirow{2}{*}{$\begin{array}{c}\mathrm{X} \\
\text { Rejection }(\%)\end{array}$} & \multirow{2}{*}{$\begin{array}{c}\mathrm{Y} \\
\text { Permeate Flux } \\
\left(\mathrm{L} /\left(\mathrm{m}^{2} \cdot \mathrm{h}\right)\right)\end{array}$} \\
\hline & & A & B & C & D & E & & \\
\hline & & 1 & 1 & 1 & 1 & 1 & 45.55 & 263.25 \\
\hline & & 1 & 2 & 2 & 2 & 2 & 17.89 & 269.82 \\
\hline & & 1 & 3 & 3 & 3 & 3 & 17.41 & 289.33 \\
\hline & & 1 & 4 & 4 & 4 & 4 & 17.30 & 298.14 \\
\hline & & 2 & 4 & 2 & 3 & 1 & 29.17 & 287.77 \\
\hline & & 2 & 3 & 1 & 4 & 2 & 26.30 & 295.27 \\
\hline & & 2 & 2 & 4 & 1 & 3 & 30.46 & 236.22 \\
\hline & & 2 & 1 & 3 & 2 & 4 & 58.98 & 243.16 \\
\hline & & 3 & 2 & 3 & 4 & 1 & 41.15 & 253.43 \\
\hline & & 3 & 1 & 4 & 3 & 2 & 67.17 & 234.83 \\
\hline & & 3 & 4 & 1 & 2 & 3 & 33.70 & 255.05 \\
\hline & & 3 & 3 & 2 & 1 & 4 & 31.00 & 228.57 \\
\hline & & 4 & 3 & 4 & 2 & 1 & 23.97 & 212.20 \\
\hline & & 4 & 4 & 3 & 1 & 2 & 35.31 & 205.30 \\
\hline & & 4 & 1 & 2 & 4 & 3 & 78.22 & 239.28 \\
\hline & & 4 & 2 & 1 & 3 & 4 & 50.07 & 247.68 \\
\hline \multirow{5}{*}{$x$} & K1 & 24.550 & 62.500 & 38.925 & 35.600 & 34.975 & & \\
\hline & $\mathrm{K} 2$ & 36.250 & 34.900 & 39.075 & 33.650 & 36.675 & & \\
\hline & K3 & 43.250 & 24.675 & 38.200 & 40.975 & 39.950 & & \\
\hline & K4 & 46.900 & 28.875 & 34.750 & 40.725 & 39.350 & & \\
\hline & $\mathrm{R}$ & 22.350 & 37.825 & 4.325 & 7.325 & 4.975 & & \\
\hline \multirow{5}{*}{$\mathrm{Y}$} & K1 & 280.13 & 245.13 & 265.31 & 233.33 & 254.16 & & \\
\hline & K2 & 265.60 & 251.78 & 256.36 & 245.05 & 251.30 & & \\
\hline & K3 & 242.97 & 256.34 & 247.80 & 264.90 & 254.97 & & \\
\hline & K4 & 226.11 & 261.56 & 245.34 & 271.52 & 254.38 & & \\
\hline & $\mathrm{R}$ & 54.020 & 16.435 & 19.962 & 38.192 & 3.667 & & \\
\hline
\end{tabular}

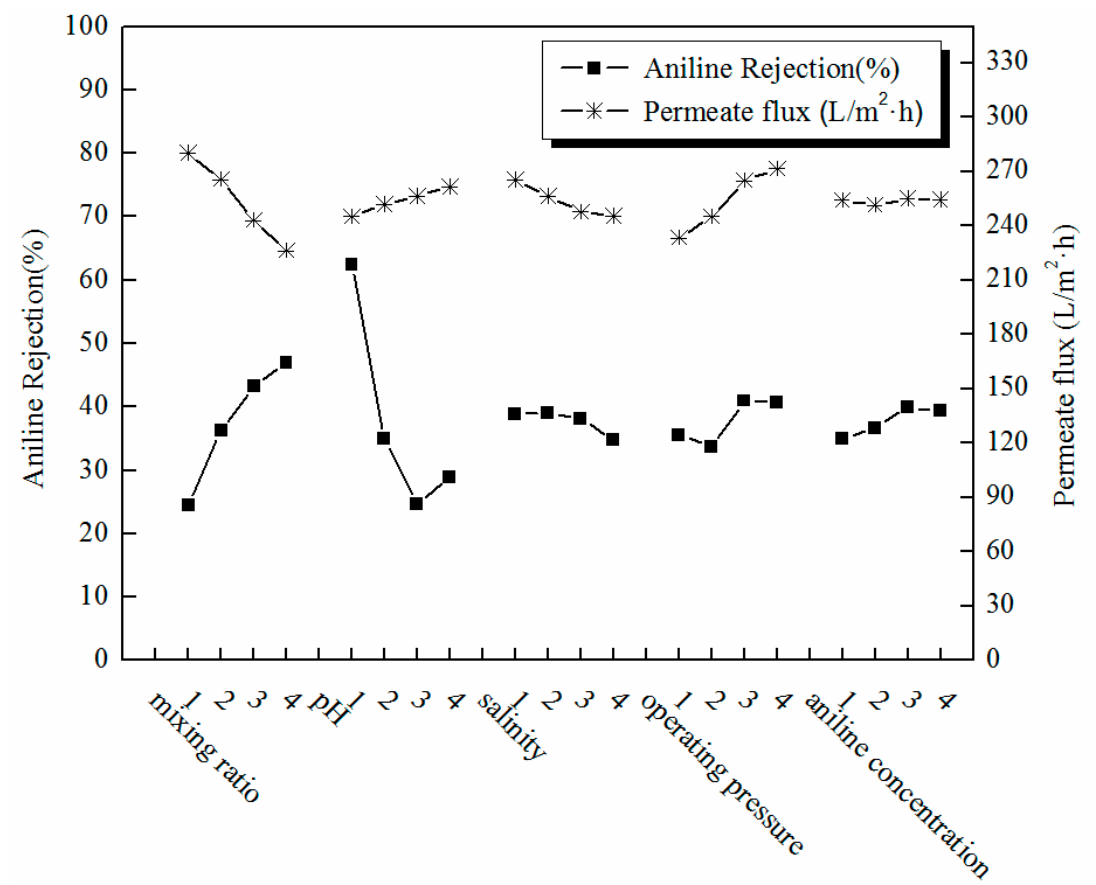

Factor and Level

Figure 7. Effect of the factors on aniline rejection and permeate flux. 


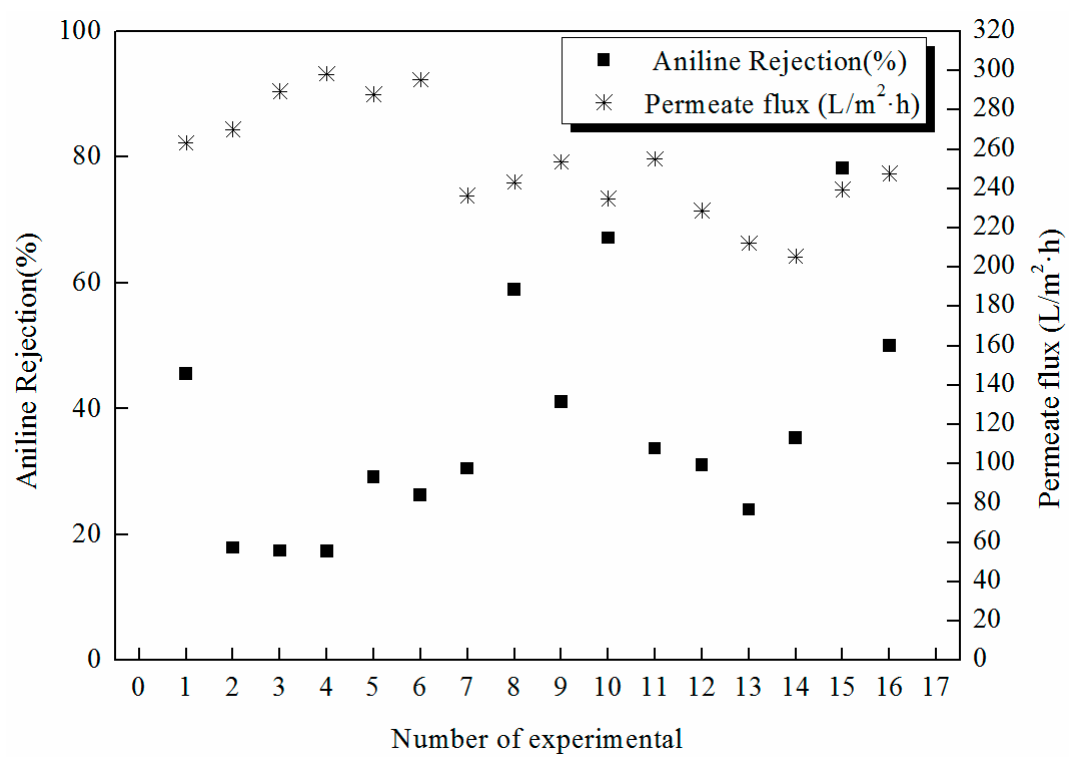

Figure 8. Aniline rejection and permeate flux of the orthogonal experiment.

The orthogonal test results show that under the fifteenth set of experimental conditions (SDS:rhamnolipid $=8: 2, \mathrm{pH}=5$, salinity $=150 \mathrm{mmol} / \mathrm{L}$, operating pressure $=3.5 \mathrm{bar}$, aniline concentration $=1.5 \mathrm{mM}$ ), the aniline rejection reached the maximum of $78.22 \%$, and the membrane permeation flux was $239.28 \mathrm{~L} /\left(\mathrm{m}^{2} \cdot \mathrm{h}\right)$; under the fourth set of experimental conditions (SDS:rhamnolipid $=2: 8, \mathrm{pH}=9$, salinity $=250 \mathrm{mmol} / \mathrm{L}$, operating pressure $=3.5 \mathrm{bar}$, aniline concentration $=2 \mathrm{mM})$, the maximum membrane permeation flux was $298.14 \mathrm{~L} /\left(\mathrm{m}^{2} \cdot \mathrm{h}\right)$, and the aniline rejection was $17.30 \%$. The range analysis results and the figures show that the factors affect the aniline rejection in the order of $\mathrm{B}>\mathrm{A}>\mathrm{D}>\mathrm{E}>\mathrm{C}$, and $\mathrm{pH}$ has the most significant influence on the aniline rejection efficiency, while salinity has the smallest influence; the optimal test condition for the aniline rejection is A4B1C2D4E3. The factors affect the membrane permeation flux in the order of $\mathrm{A}>\mathrm{D}>\mathrm{C}>\mathrm{B}>\mathrm{E}$, and the mixing ratio has the most significant influence on the membrane flux, while the influence of the aniline concentration is the smallest; the optimal test condition for the membrane flux is A1B4C4D4E4. A comprehensive analysis shows that the influences of factor $\mathrm{A}$ on the aniline rejection and the membrane permeation flux are second-most and most important, so A4 and A1 are used. In the case of A4, the aniline rejection increases by $87.6 \%$ compared with the case of $\mathrm{A} 1$, while the membrane flux decreases by $19.3 \%$, so the A factor is set to A4. Similarly, the B factor is set to B1, the C factor is set to C4, the D factor is set to $\mathrm{D} 4$, and the $\mathrm{E}$ factor is set to $\mathrm{E} 3$. Therefore, the optimal test condition for the aniline rejection and the membrane permeation flux is A4B1C4D4E3. The optimal test conditions (SDS:rhamnolipid = 8:2, $\mathrm{pH}=5$, salinity $=250 \mathrm{mmol} / \mathrm{L}$, operating pressure $=3.5 \mathrm{bar}$, aniline concentration $=1.5 \mathrm{mM}$ ) were studied by a verification test, which showed an aniline rejection of $78.36 \%$ and a membrane permeation flux of $245.36 \mathrm{~L} /\left(\mathrm{m}^{2} \cdot \mathrm{h}\right)$.

\section{Conclusions}

The analysis of the test results shows that the studied factors affect the aniline rejection in the order of $\mathrm{pH}>$ mixing ratio $>$ operating pressure $>$ aniline concentration $>$ salinity, and that the factors affect the membrane permeation flux in the order of mixing ratio $>$ operating pressure $>$ salinity $>\mathrm{pH}$ $>$ aniline concentration. A comprehensive analysis shows that the optimal test plan was A4B1C4D4E3. Under the optimal test conditions (i.e., SDS:rhamnolipid $=8: 2, \mathrm{pH}=5$, salinity $=250 \mathrm{mmol} / \mathrm{L}$, operating pressure $=3.5 \mathrm{bar}$, aniline concentration $=1.5 \mathrm{mM})$, the verification test results showed an aniline rejection of $78.36 \%$ and a membrane permeation flux of $245.36 \mathrm{~L} /\left(\mathrm{m}^{2} \cdot \mathrm{h}\right)$. 
Acknowledgments: This work was financially supported by National Natural Science Foundation of China (51109181), Foundation of Fujian Educational Committee (JA11236, JA14238), Foundation of Xiamen University of Technology(XYK201417).

Author Contributions: Hai-Yan Fu and Guo-He Huang conceived and designed the experiments; Zhi-Bin Zhang and Shu-Jie Yu performed the experiments; Tian Chai and Zheng Liu analyzed the data; Pang-Feng Gao contributed reagents tools; Hai-Yan Fu wrote the paper.

Conflicts of Interest: The authors declare no conflict of interest.

\section{References}

1. Lee, S.H.; Shrestha, S. Application of micellar enhanced ultrafiltration (MEUF) process for zinc (II) removal in synthetic wastewater: Kinetics and two-parameter isotherm models. Int. Biodeterior. Biodegrad. 2014, 95, 241-250. [CrossRef]

2. Gao, D.W.; Hu, Q.; Pan, H.; Jiang, J.; Wang, P. High-capacity adsorption of aniline using surface modification of lignocellulose-biomass jute fibers. Bioresour. Technol. 2015, 193, 507-512. [CrossRef] [PubMed]

3. Li, B. Electro-Dialysis Treatment of Aniline Wastewater; Beijing University of Chemical Technology: Beijing, China, 2011.

4. Zuo, L.N.; Song, W.Z.; Shi, T.H.; Lv, C.; Yao, J.; Liu, J.F.; Weng, Y.H. Adsorption of aniline on templatesynthesized porous carbons. Microporous Mesoporous Mater. 2014, 200, 174-181. [CrossRef]

5. Tao, Y.; Wang, X.; Lv, C.; Zhang, F.J.; Wu, Y.W.; Sun, J. Study on the treatment of aniline wastewater by vacuum membrane distillation. Water Treat. Technol. 2012, 38, 45-48. (In Chinese)

6. Fu, H.Y.; Xu, P.C.; Huang, G.H.; Chai, T.; Hou, M.; Gao, P.F. Effects of aeration parameters on effluent quality and membrane fouling in asubmerged membrane bioreactor using Box-Behnken response surface methodology. Desalination 2012, 302, 33-42. [CrossRef]

7. Zhang, W.X.; Huang, G.H.; Wei, J.; Yan, D. Geminimicellar enhanced ultrafiltration (GMEUF) process for the treatment of phenol wastewater. Desalination 2013, 311, 31-36. [CrossRef]

8. Huang, J.H.; Peng, L.; Zeng, G.N.; Li, X.; Zhao, Y.; Liu, L.X; Li, F.; Chai, Q. Evaluation of micellar-enhanced ultrafiltration for removing methylene blue and cadmium ion simultaneously with mixed surfactants. Sep. Purif. Technol. 2014, 125, 83-89. [CrossRef]

9. Zhang, W.X.; Huang, G.H.; Wei, J.; Li, H.Q.; Zheng, R.B.; Zhou, Y. Removal of phenol from synthetic waste water using Gemini Micellar-Enhanced ultrafiltration (GMEUF). J. Hazard. Mater. 2012, 235, 128-137. [CrossRef] [PubMed]

10. Valentina, I.; Francesco, T.; Marina, P.; Giuseppe, M.D.C.; Francesco, V. Zinc and chromium removal from liquid wastes by using micellar enhanced ultrafiltration. Desalin. Water Treat. 2017, 61, 250-256.

11. Francesco, T.; Valentina, I.; Marina, P.; Francesco, V.; Giuseppe, M.D.C. Heavy Metal Removal from Liquid Wastes by Using Micellar-Enhanced Ultrafiltration. Water Air Soil Pollut. 2016, 227, 1-11.

12. Tanhaei, B.; PourafshariChenar, M.; Saghatoleslami, N.; Hesampour, M.; Laakso, T.; Kallioinen, M.; Sillanpaa, M.; Manttari, M. Simultaneous removal of aniline and nickel from water by micellar enhanced ultrafiltration with different molecular weight cut-off membranes. Sep. Purif. Technol. 2014, 124, $26-35$. [CrossRef]

13. Bodagh, A.; Khoshdast, H.; Sharafi, H.; Shahbani Zahiri, H.; Akbari Noghabi, K. Removal of Cadmium(II) from Aqueous Solution by Ion Flotation Using Rhamnolipid Biosurfactant As an Ion Collector. Ind. Eng. Chem. Res. 2013, 52, 3910-3917. [CrossRef]

14. Shekhar, S.; Sundaramanickam, A.; Balasubramanian, T. Biosurfactant Producing Microbes and their Potential Applications: A Review. Environ. Sci. Technol. 2015, 45, 1522-1554. [CrossRef]

15. Abbasi-Garravand, E.; Catherine, N.M. Using ultrafiltration and reduction techniques for removal of $\mathrm{Cr}(\mathrm{VI})$ and Cr(III) from water. Sep. Purif. Technol. 2014, 132, 505-512. [CrossRef]

16. Zhong, H.; Liu, Y.; Liu, Z.F.; Jiang, Y.B.; Tan, F.; Zeng, G.M.; Yuan, X.Z.; Yan, M.; Niu, Q.Y.; Liang, Y.S. Degradation of pseudo-solubilized and mass hexadecane by a Pseudomonas aeruginosa with treatment of rhamnolipid biosurfactant. Int. Biodeterior. Biodegrad. 2014, 94, 152-159. [CrossRef]

17. Lan, G.H.; Fan, Q.; Liu, Y.Q.; Chen, C.; Li, G.X.; Liu, Y.; Yin, X.B. Rhamnolipid production from waste cooking oil using Pseudomonas SWP-4. Biochem. Eng. J. 2015, 101, 44-54. [CrossRef] 
18. Fu, H.Y.; Chai, T.; Huang, G.H.; Gao, P.F.; Liu, Z.F. Effects of rhamnolipid on the adsorption of $\mathrm{Pb}^{2+}$ onto compost humic acid. Desalin. Water Treat. 2015, 54, 3177-3183. [CrossRef]

19. Lu, S.J.; Sun, Z.J.; Teng, Y.G.; Wang, J.S. Effect of Single and Mix Surfactants on Degradation of Diesel Oil by Microorganism. Environ. Sci. Manag. 2010, 35, 42-46. (In Chinese)

20. Zeng, G.M.; Xu, K.; Huang, J.H.; Li, X.; Fang, Y.Y.; Qu, Y.H. Micellar-enhanced ultrafiltration of phenol in synthetic wastewater using polysulfone spiral membrane. J. Membr. Sci. 2008, 310, 149-160. [CrossRef]

21. Purkait, M.K.; DasGupta, S.; De, S. Removal of dye from wastewater using micellar-enhanced ultrafiltration and recovery of surfactant. Sep. Purif. Technol. 2004, 37, 81-92. [CrossRef]

22. Monem, E.L.; Zeftawy, M.A.; Catherine, N.M. Use of rhamnolipid to remove heavy metals from wastewater by micellar enhanced ultrafiltration (MEUF). Sep. Purif. Technol. 2011, 77, 120-127. [CrossRef]

23. Huang, J.H. Research on the Mechanism and Application of Micellar-Enhanced Ultrafiltration Treatment of Cadmium Wastewater; Hunan University: Changsha, China, 2007. (In Chinese)

(C) 2017 by the authors. Licensee MDPI, Basel, Switzerland. This article is an open access article distributed under the terms and conditions of the Creative Commons Attribution (CC BY) license (http:/ / creativecommons.org/licenses/by/4.0/). 